\title{
Sharps disposal practices among diabetic patients using insulin
}

D Govender, A Ross

Insulin-dependent diabetic patients are not educated on safe sharps disposal methods, so leading to unsafe disposal of needles. Appropriate education on the correct disposal of sharps should be an integral part of their diabetic counseling. Doctors, nurses and pharmacists should all take responsibility for educating and reinforcing information about correct sharps disposal methods. Patients should be advised to either discard sharps into punctureresistant containers placed into their household refuse, or return them in secure containers for disposal by the dispensing institutions. Patients should also be educated regarding health risks associated with used needles. The South African Metabolic and Endocrine (SEMDSA) Guidelines and the South African Standard Treatment Guidelines (STG) should also give clear guidance on the safe disposal of needles.

S Afr Med J 2012;102:163-164.
Diabetes is conservatively estimated to occur in 4 million South Africans. ${ }^{1}$ All type 1 , and up to $40 \%$ of type 2 , diabetic patients require insulin therapy. ${ }^{1}$ With so many patients using insulin, much medical waste is generated daily in the form of used needles and syringes.

Used sharps are a biomedical hazard as incorrect disposal could lead to needle-stick injuries (NSIs), ${ }^{2}$ posing the risk of contracting human immunodeficiency virus (HIV), hepatitis B or C and other blood-borne diseases. ${ }^{2}$ An individual not protected by prior hepatitis vaccination who sustains an NSI from a needle used by an individual testing positive for hepatitis B surface antigen has a 6 - 30\% chance of infection by the virus. ${ }^{2}$ The risk of HIV infection following one percutaneous exposure to HIV-infected blood is estimated to be $0.3 \% .^{2}$ South Africa has a high prevalence of $\mathrm{HIV}^{3}$ and, with many diabetic patients likely to have HIV or other transmittable infections, safe sharps disposal practices are essential.

South Africa's constitution states: 'Everyone has the right to an environment that is not harmful to their health and well-being.' Sharps disposal is a problem in South Africa because of accidental NSI to garbage removers or other persons handling domestic waste. ${ }^{5}$ The 2009 Health Care Waste Summit ${ }^{6}$ recognised the problems with sharps disposal in South Africa. The safe disposal of needles and lancets used by insulin-dependent diabetic patients is not only a problem in South Africa; in 1989, 109 NSIs were formally reported by garbage collectors in the Atlanta metropolitan area, ${ }^{2}$ and other studies in Atlanta and European countries have highlighted the problem of incorrect sharps disposal practices by patients at home., ${ }^{2,7}$

In 1998, Macalino et al. investigated community-based programmes for safe disposal of used needles in the USA, Canada and Australia; ${ }^{8}$ these included using puncture-resistant containers such as hotchocolate or coffee containers with a secure lid and discarding these in the household rubbish. Other safe disposal methods included using community drop-boxes where used sharps could be deposited, and the use of sharps containers sent for safe biohazard disposal at community sites, hospitals and pharmacies.

In 1990, the American Diabetes Association, and in 2002 Diabetes $\mathrm{UK}$, issued recommendations that all needles and lancets used by diabetic patients be placed into a puncture-resistant container before

Department of Family Medicine, University of KwaZulu-Natal, Durban D Govender, $\mathrm{MB} \mathrm{ChB}$

A Ross, MB ChB, DCh, MFamMed discarding into household waste. ${ }^{2}$ The South African Metabolic and Endocrine (SEMDSA) Guidelines ${ }^{9}$ and the South African Standard Treatment Guidelines (STG) $)^{10}$ do not provide recommendations on the safe disposal of used needles and stylets. Many studies highlight the need for healthcare workers to provide the necessary skills and education to diabetic patients for safe disposal of needles. ${ }^{25,511}$

We investigated current methods of sharps disposal by diabetic patients attending Wentworth Hospital (WWH)'s outpatient department, to compare these practices with the education received by patients about correct sharps disposal, and to make recommendations regarding the safe disposal of sharps by diabetic patients.

\section{Methods}

Wentworth Hospital is a district-level hospital in Durban that sees almost 12000 outpatients per month. The hospital pharmacy dispenses monthly just under 5000 insulin pensets, each with a needle, to patients. There is no record of any sharps being returned to the hospital for disposal.

The study included insulin-dependent diabetic patients over the age of 18 years attending WWH OPD who consented to participate. In consultation with a biostatistician, a sample of 132 diabetic patients using insulin was chosen. The sample size was based on the assumption that the population prevalence of incorrect needle disposal was $90 \%$ and was calculated to give a precision level of $5 \%$. To ensure representation of all the racial groups treated at $\mathrm{WWH}$, the sample was stratified into 45 Indian, 44 black, 36 coloured and 7 white patients. It was assumed that patients present in a random order to OPD, so convenience consecutive sampling from the OPD bench was used to collect data from diabetic patients using insulin. The study took place from October to December 2010. Questionnaires on current practices regarding insulin needle disposal and on education received regarding sharps disposal were administered to each participant by the principal investigator. Data were entered onto an Excel spreadsheet and the SPSS computer software package used to analyse the data. Factors associated with correct disposal methods were analysed using Pearson's chi square tests. A $p$-value $<0.05$ was considered to be statistically significant.

\section{Results}

The ages of the study population ranged from 18 to 86 years (mean 58.3 years); most had type 2 diabetes; $29 \%$ were male and $71 \%$ were female; 4 (3\%) were younger than 25 years, $3(2.2 \%)$ were 25 - 39 years old, $64(48 \%)$ were 40 - 59 years old, and $62(46.2 \%)$ were $>60$ years old. Nine patients had received no formal education; 31 had only attended primary school, 84 attended secondary school, and 8 had tertiary education. 
Each month, 850 needles were generated by the 132 patients. Needles were re-used 2 - 20 times by patients; 117 (88\%) patients disposed of used needles directly into their household rubbish bins, 8 (6\%) flushed used needles down the toilet into the sewage system, and $4(3 \%)$ used other methods such as burying the needles (Fig. 1). Only 3 (2.2\%) patients returned their needles in puncture-resistant containers to the hospital for disposal. No associations were found between race, gender, education levels and correct disposal of used sharps. Forty-six (35\%) patients were aware of the potential health risks associated with injury caused by the incorrect disposal of used needles.

Of the participants, $91 \%$ (120/132) had received diabetic education and counselling regarding insulin use, storage and administration; $68 \%$ (89) rated the diabetic education as good, $22.7 \%$ rated it average, and $9.7 \%$ as poor. Despite the positive response to the education provided on use and storage of insulin, only $5(3.8 \%)$ patients stated that they had received education and counselling regarding correct methods of sharps disposal. All 3 patients who were correctly disposing of their needles had been educated about how to do so.

There was a highly significant association between education received by patients and correct needle disposal methods $(p<0.001)$. Of the 5 who were educated in disposal, $60 \%$ correctly disposed of the needles whereas, of the 127 who were not educated in disposal, none correctly disposed of the needles.

\section{Discussion}

The race groups recruited for the study are representative of the patient population with diabetes seen at WWH. The data show that over $97 \%$ of the study population discarded their sharps inappropriately. The lack of association between race, gender or education levels and correct needle disposal practices was surprising, as those with a higher level of education could be expected to be better educated about their disease and recognise the hazardous nature and need for safe disposal of their medical waste.

No recent studies were found on safe disposal of sharps by diabetic patients. However, our findings are consistent with studies in the early 1990s in Europe and the USA, ${ }^{2}$ highlighting the fact that needle disposal is a global problem in the developed and developing world.

The large number of patients who dispose of their needles incorrectly is of concern. The National Environmental Management Act of 1998 states that the duty of care principle requires the generator of hazardous waste, under all circumstances, to carry the responsibility of the ultimate fate of the generated waste. ${ }^{4}$ Patients, healthcare workers or healthcare facilities could be liable for costs associated with treating garbage collectors who can prove that they were infected from contaminated needles. This serious issue requires urgent attention from health professionals, who have a responsibility to provide information to patients about safe disposal of needles.

Deficiencies in diabetic education and counselling provided to diabetic patients have been highlighted. Emphasis is placed on knowledge regarding storage and administration of insulin, but very little counselling is provided on correct sharps disposal. Less than $4 \%(5 / 132)$ of our patients had received any counselling about correct sharps disposal practices. It is disappointing to note that since 2009, when disposal of needles and other hazardous material was identified as a serious issue at the Health Care Summit, ${ }^{6}$ more emphasis has not been placed on safe needle disposal.

Despite much work on needle-free products for the administration of insulin, progress has been slow and inconsistent, ${ }^{12}$ and no significant needle-free alternative method of insulin administration is available. As needles will continue to be part of diabetic care by all patients requiring insulin for some time to come in South Africa and other countries, their safe disposal must therefore form an integral part of diabetic education.

Although this study's numbers are small and the results must be treated with caution, they suggest that appropriate education and knowledge on sharps disposal is the most important determining factor in correct disposal methods.

\section{References}

1. Katz I, Mdleleni G, Shezi EZ, Butler O, Gerntholtz T. Strategies for the early detection and management of chronic kidney disease - tertiary and primary health care working together. CME 2007;25(8):360365 .

2. Satterfield D, Kling J. Diabetes educators encourage safe needle practice. Diabetes Educator 1991;17:321-325.

3. Nicoll A, Gill ON. The global impact of HIV infection and disease. Commun Dis Public Health 1999;2(2): 85-95

4. Department of Health, KwaZulu-Natal. Health Care Risk Waste Management Policy for KwaZuluNatal Province. Pietermaritzburg: Department of Health, 2008.

McConville DE, Hamilton EM. Syringe disposal practices and gender differences. Diabetes Educator 2002;28:91-98.

6. Bothma J. Health care waste summit 2009. SA Pharmaceutical Journal 2009; July:37-38.

. Bouhanick B, Hadjadj S, Weekers L. What do the needles, syringes, lancets and reagent strips of diabetic patients become in the absence of a common attitude? Diabetes Metab 2000;26:288-293.

8. Macalino GE, Springer KW, Rahman ZS, Vlahov D, Jones TS. Community-based programs for safe disposal of used needles and syringes. J Acquir Immune Defic Syndr Hum Retrovirol 1998;18 Suppl 1:S111-119.

9. SEMDSA guidelines for the diagnosis and management of type 2 diabetes mellitus for primary health care. Journal of Endocrinology, Metabolism and Diabetes of South Africa 2009;14(1):55-58.

10. Standard Treatment Guidelines and Essential Drug List. Pretoria: National Department of Health, 2006 11. Crawshaw G, Irwin DJ, Button J. Disposal of syringes, needles and lancets used by diabetic patients in
North East Essex. Commun Dis Public Health 2002;5:134-137.

12. Heinemann L. New ways of insulin delivery. Int J Clin Pract 2010;166 suppl:S29-40.

Accepted 27 September 2011. 